\title{
Business Exploration in Meteorological Disaster Risk Management Based on Big Data
}

\author{
Xiaolei Chen \\ Hebei Meteorological Disaster Prevention Center \\ Shijiazhuang 050021, China \\ sjz_cxl@aliyun.com \\ 基于大数据的气象灾害风险管理业务探索 \\ 陈小雷 \\ 河北省气象灾害防御中心 \\ 石家庄 050021，中国 \\ sjz_cxl@aliyun.com
}

\begin{abstract}
Based on the needs of supporting business in meteorological disaster risk management, this article firstly analyze the characteristics of big data and the connotation of meteorological big data, and clarifies the concept of the big data for meteorological disaster defense, which are composed of five major types of data such as disaster situation. We also explore how to apply artificial intelligence, experience method, screening method and other technical methods to expand the construction of big data for meteorological disaster defense. Then, we summarized the practical experience of using big data in meteorological disaster monitoring and evaluation, meteorological disaster risk zoning, meteorological disaster risk forecasting and early warning, risk management business system construction, etc. A future development is proposed.
\end{abstract}

Keywords-meteorological disaster, big data, risk management, application exploration

摘要一本文从分析大数据特性和气象大数据内涵 入手，基于支撑气象灾害风险管理业务的需要，明确 了由灾情等五大类数据构成的气象灾害防御大数据 概念, 探索了如何应用人工智能、经验法、篇选法等 多种技术方法去拓展气象灾害防御大数据建设, 总结 了利用大数据在气象灾害监测评估、气象灾害风险区 划、气象灾害风险预报预警、风险管理业务系统建设 等方面的实践经验, 并提出了今后发展建议。

\footnotetext{
关键词一气象灾害，大数据，风险管理，应用探
}

\section{I. 引言}

当前, 大数据已成为全球社会和技术发展的 热点, 各国政府和国际组织纷纷将开发利用大数 据作为夺取新一轮竞争制高点的重要抓手。美国 2012 年发布 “大数据研发计划”, 重点研究分析 大数据在医疗、天气和国防等领域应用。德国 2010 年发表《德国 ICT 战略: 数字德国 2015》, 提出了如何利用大数据应用来促进未来发展。 ICT 是 Institute of Computing Technology 的 缩写，即，信息通信技术。英国政府投入大量资 金, 率先利用大数据在交通、天气、健康等方面 开展应用分析研究。日本 2012 年发布了以大数 据为亮点的“活跃 ICT 日本新战略” ${ }^{[1]}$ 。2015 年, 中国政府印发了《促进大数据发展行动纲要》, 国土资源部、农业部、环保部、贵州省、北京市 等纷纷印发促进大数据发展的实施意见。可以说， 大数据发展应用受到国内外各级政府、社会及学 术界、产业界高度关注 ${ }^{[2]}$ 。

气象部门作为典型的信息部门, 高度重视气 象大数据应用工作。2016 年, 中国气象局在《全 国气象发展 “十三五” 规划》中明确提出, 落实 国家 “互联网+” 行动和大数据发展战略, 推进 云计算、大数据、物联网、移动互联网等技术的 气象应用。2017 年, 中国气象局在《关于加强气 象防灾减灾救灾工作意见》中提出，应用大数据 和人工智能技术, 搭建气象大数据人工智能算法 
平台, 推进气象数据与多领域数据的融合应用, 为决策者应对各类突发事件提供数据和技术支 持。同时, 在大数据应用方面也开展了一系列的 工作, 包括了气象行业数据采集、质控、存储、 处理、加工分析应用和服务等方面。但是, 气象 大数据在如何开拓数据源、充分利用互联网气象 数据方面还有一定的差距, 特别是在数据收集的 质量控制、时效性方面不够强，支撑气象防灾减 灾和气象风险管理业务的灾害防御基础数据方 面收集广度和深度不够、标准不统一等。对此, 本文从如何利用新技术、新手段来开拓气象数据 收集渠道方面进行了探讨, 并把收集的气象大数 据如何在气象灾害风险管理业务的应用进行了 尝试。

\section{II. 气象灾害防御大数据是大数据重 要组成部分}

\section{A. 大数据的特性}

目前大数据还没有确切的定义。狭义地讲, 大数据是海量数据, 是指大小超过一定量级的数 据, 美国著名的麦肯锡公司给出一个狭义的大数 据定义: 大数据是指大小超出常规软件获取、存 储、管理和分析能力的数据 ${ }^{[3]}$ 。但是从大数据广 义地讲, 大数据不只是量大的数据, 它更加强调 数据来源的广泛性和全社会的广泛应用, 大数据 具有大容量、多样性、时效性、不精确性和低价 值特征, 且传统手段已经难于管理和有效发挥其 价值的、具有社会广泛应用的数据集。

\section{B. 气象大数据的内涵}

气象大数据概括来讲, 就是指所有与气象工 作相关的数据总和, 从来源渠道上划分可分为 气象行业大数据和气象互联网大数据两类 ${ }^{[4]}$ 。气 象行业大数据由与气象部门各项工作相关且产 生自气象及相关部门内部的所有数据组成, 它属 于气象业务数据。气象互联网大数据由互联网上 与气象相关的所有数据所组成, 包括移动终端、 交通工具、网友随拍、搜索引擎等探测到的气象 数据, 它不是专业气象数据, 它来自非气象部门 的行业、企业以及个人等, 但这些数据又包含着 与特定气象应用的信息内容, 而且其恰恰是气象 行业大数据所缺乏的, 可以说其未来发展前景是 无限的。

\section{C. 气象灾害防御大数据的内容}

气象灾害风险管理是做好气象灾害防御的 重要工作之一。气象灾害风险管理就是为减轻气
象灾害风险, 对其进行风险识别、风险估测、风 险评价, 并在此基础上对风险实施有效地控制, 妥善处置风险损失的后果, 期望达到以最小的成 本获得最大的安全保障的措施与行动 ${ }^{[5]}$ 。气象灾 害风险研究的基本理论表明, 气象灾害风险由致 灾因子、承灾体的脆弱性和暴露度三者构成。气 象灾害风险不仅取决于致灾因子的严重程度, 也 在很大程度上取决于承灾体的脆弱性和暴露度 的水平。因此, 开展气象灾害风险管理业务离不 开气象大数据的支撑, 更离不开其它行业大数据 的支撑, 例如水文大数据、地质大数据、灾情大 数据、社会经济大数据等。

基于支撑气象灾害风险管理业务的需要, 气象灾害防御大数据可包括灾情数据、致灾因子 数据、承灾体数据、孕灾环境数据和防灾减灾能 力数据等五大类。其中灾情数据是核心, 它更具 有大数据来源的广泛性特征, 包括因气象灾害造 成的受灾经济损失、农作物受灾面积、受灾人口、 房屋倒塌等; 致灾因子数据是描述气象要素特征 的数据, 例如降雨强度、降雨量、风速等; 承灾 体数据包括人口、土地、道路、学校、医院、车 站、水库、地质灾害隐患点等数据; 孕灾环境数 据包括土壤性质、高程、地形、水系等数据; 防 灾减灾能力数据包括灾害监测设备、避难场所、 防灾设施等数据。目前已建成以灾情数据为核心, 包括致灾因子、承灾体、孕灾环境和防灾减灾能 力等五大类数据, 涉及 116 种数据的气象灾害防 御大数据库。

\section{III. 气象灾害防御大数据多源获取技术}

\section{A. 建立多源气象灾情信息采集渠道}

一是整合气象部门内部灾情渠道, 实现包括 气象灾情直报、现场调查、灾害风险专项普查等 数据的规范采集入库。二是加强部门信息共享, 开展与应急、水利、自然资源等部门合作，加强 部门之间信息交换。三是积极拓展多源社会化灾 情采集渠道, 实现网络媒体、微博、微信、志愿 者等实时灾情的即时上报。

\section{B. 建立历史长序列气象灾情数据集}

拓展历史灾情源, 制定气象灾情纸质资料数 字化标准, 全面整理《气象灾害大典》、《中国三 千年气象灾害总集》、《河北省地方志》等文献史 料记载的历史灾情数据, 建立了公元前 781 年以 来的河北省历史长序列气象灾情数据集。 


\section{C. 挖掘应用人工智能技术}

人工智能技术是进行大数据分析的一种重 要方法, 机器学习、计算智能都属于人工智能技 术中重要的分析方法, 其中深度学习具有卓越的 性能, 是目前最重要的机器学习方法 ${ }^{[6]}$ 。利用人 工智能技术在社会化气象灾情信息收集上进行 了探索, 一是利用图像识别与机器学习技术, 对 众包图像数据进行识别分类, 拓展气象灾情收集 渠道。搭建深度学习环境, 构建暴雨、暴雪、冰 霞、雾皬、内涝、滑坡、泥石流、倒塌等可供学 习的图像资源库, 建立灾害识别模型。二是梳理 互联网灾情信息, 建立通用+专有关键词库, 利 用自然语言处理、网络爬虫等技术，建立了 18 个灾种文字模型, 进一步扩大气象灾情信息收集 渠道。

\section{IV. 大数据在气象灾害风险管理业务 中应用探索}

\section{A. 开展气象灾害过程监测、识别和评估分析}

在气候变化的大背景下, 灾害性天气气候特 征及发生规律正在发生改变, 对收集的各类气象 灾害防御大数据进行分析整理, 总结灾情空间分 布、变化趋势特征, 为重新认识气象灾害变化规 律奠定了基础。例如, 通过对 1470-2014 年河北 省旱涝资料分析, 探讨了河北省 545 年的旱涝类 型变化特征及其演变规律 ${ }^{[7]}$ 。通过对河北省多年 大风资料和灾情数据分析, 研究了河北省大风灾 害特征及其危险性区划 ${ }^{[8]}$ 。利用 2005-2014 年气 象灾情数据, 探讨了气象灾害对河北省农业生产 的风险影响 ${ }^{[9]}$ 。通过对 2016 年 7月 19-21 日大暴 雨过程的资料分析, 揭示了此次暴雨洪涝灾害的 成因、特点等 ${ }^{[10]}$ 。

\section{B. 开展气象灾害风险地图与区划技术研究}

以气象灾害防御大数据为基础, 应用 GIS 和 遥感技术, 综合评估气象灾害危险性、脆弱性和 气象灾害风险等, 开展了河北省气象灾害风险地 图和区划技术研究, 建立了气象灾害风险评估数 据库, 构建了 31 种致灾因子与 37 种承灾体数据 关系模型, 采用时相-多尺度自然灾害风险评估 技术、现代地图综合技术，编制了含有 12 个灾 种的河北省气象灾害风险地图集, 其中在暴雨洪 涝灾害风险评估中用到了大数据库中全省 142 个 气象站 30 年的降水资料、3047 个区域气象站 10 年的降水资料、全省 30 年灾情数据资料以及全 省主要农作物分布、人口、经济等数据资料 ${ }^{[11]}$ 。
C. 开展致灾阈值和基于影响的风险预报预警技 术研究

所谓致灾阈值, 就是可能引发人员伤亡、财 产损失及资源破坏等气象灾害的气象致灾因子 临界值 ${ }^{[12]}$ 。由于自然灾害的发生不仅与致灾因子 有关, 而且与孕灾环境、防灾设施能力等因素有 关。因此, 研究致灾阈值必须要有足够多的灾损 资料、致灾因子样本、孕灾环境数据、防灾设施 能力数据等支撑 ${ }^{[13]}$ 。基于历史灾情数据, 对暴雨 洪涝、大风、冰霄三种灾害进行了风险评估技术 研究，形成了分灾种的灾损曲线、致灾阈值以及 定量风险评估模型等成果, 开展了山洪灾害气象 预警、设施农业大风灾害风险等级预报以及城市 内涝灾害风险预报业务。

D. 气象灾害风险管理业务系统建设

据气象灾害防御需求, 基于灾害防御大数据 库, 开发了具有 “四个一” 功能的气象灾害防御 决指挥平台, 建立了灾害风险综合监测一张网、 灾害风险综合分析研判一张图、灾害风险定量评 估一系统、灾害防御应急联动指挥一平台, 实现 了对各种承灾体信息智能关联分析和灾害风险 综合研判, 为气象灾害防御决策指挥和应急联动 提供了技术支撑。

\section{V. 相关建议}

一是加大灾害防御基础大数据库及其标准 化建设, 为数据共享应用提供支撑; 二是充分运 用数据挖掘技术，进一步推动大数据、云计算、 地理信息等新技术在气象灾害风险分析、风险评 估等方面的应用研究; 三是拓展气象灾情信息收 集渠道，建立具有智能关联技术支撑的灾害防御 业务平台; 四是大力培养有气象知识背景的大数 据分析专业人才队伍建设; 五是加强对外技术合 作，提高灾害风险管理业务科技支撑能力。

\section{参考文献}

[1] 中国气象发展研究中心, 全国气象发展 “十三五” 规划 辅导读本，北京: 气象出版社，2017 年, pp. 72-73.

[2] 谭永杰, 文敏, 朱月勤等, “地质数据的大数据特性研究, ” 中国矿业，2017 年第 9 期，pp. 67-71, 2017.

[3] 张素芳, 翟俊海, 王聪等, “大数据与大数据机器学习, ” 河北大学学报 (自然科学版), Vol. 38 , issue 3, pp. 299-308 , 2018.

[4] 中国气象发展研究中心, 全国气象发展 “十三五” 规划 
辅导读本, 北京: 气象出版社, 2017 年, pp. 78-79.

[5] 矫梅燕等, 中国气象百科全书 .气象服务卷, 北京:气象 出版社, 2016 年, pp. 139 .

[6] 王万良, 张兆娟, 高楠等, “基于人工智能技术的大数据 分析方法研究进展, ”计算机集成制造系 统, Vol. 25, issue 3, pp. 529-547, 2019.

[7] 魏军, 陈小雷, 俞海洋等, “1470-2014 年河北省旱涝灾害 特征研究, ”干旱区资源与环境, Vol. 30, issue 12, pp. 103-109, 2016.

[8] 孙霞, 陈小雷, 俞海洋等, “河北省大风灾害及其危险性 区划分析，”中国农学通报，Vol. 32, issue 1, pp. 183-187, 2016.

[9］陈小雷, “气象灾害对农业经济的风险影响分析, ” 中 国高新技术企业，Vol. 30，pp. 193-194, 2016.

[10］陈小雷, 王丽荣, 赵铁松等, 河北省暴雨洪涝灾害评估, 北京: 气象出版社, 2017 年, pp. 26-44.

[11］陈小雷, 王瑛等, 河北省气象灾害风险地图集, 北京: 科 学出版社, 2018 年, pp. 190-191.

[12］矫梅燕等, 中国气象百科全书 .气象服务卷, 北京: 气 象出版社, 2016 年, pp. 147.

［13］章国材, 自然灾害风险评估与区划原理和方法, 北京: 气象出版社, 2013 年, pp. 29-30. 